\title{
CELLULOSE NANOCRYSTALS DERIVED FROM OIL PALM EMPTY FRUIT BUNCH REINFORCED NATURAL RUBBER LATEX NANOCOMPOSITES
}

\author{
INTAN SYAHIERA AZLI'; AFKAR RABBANI HIDAYATULLAH HIPENI ${ }^{2}$ \\ and KHAIRATUN NAJWA MOHD AMIN ${ }^{2 *}$
}

\begin{abstract}
Natural rubber latex (NRL) has long been used in lots of application in elastomer industry. However, finished products may develop pinholes or tear easily while being used. Thus, cellulose nanocrystal (CNC) was used as reinforcing filler in NRL to overcome this problem. CNC from cellulose derived from oil palm empty fruit bunch (EFB) was isolated via sulphuric acid hydrolysis method. The CNC concentration added to the NRL was varied at 1, 3 and $5 \mathrm{wt. \%}$. The effect of $C N C$ addition and curing temperature of $70^{\circ} \mathrm{C}$ and $100^{\circ} \mathrm{C}$ of NRL on the mechanical properties, functional group presence, glass transition temperature $\left(T_{8}\right)$ and swelling behaviour of CNC/NRL nanocomposite were studied. The morphology of CNC with needle-like shape, length of $672 \pm 445 \mathrm{~nm}$, and diameter of $103 \pm 39 \mathrm{~nm}$ was determined by using field emission scanning electron microscopy (FESEM). The best nanocomposites performance with low CNC loading of 1 wt.\% has successfully increased the tensile strength and elongation at break with $20 \%$ and $14 \%$ of improvement, respectively at $70^{\circ} \mathrm{C}$ of curing temperature.
\end{abstract}

Keywords: anaerobic-aerobic, biogas, biological oxygen demand, palm oil.

Received: 16 July 2021; Accepted: 31 December 2021; Published online: 15 February 2022.

\section{INTRODUCTION}

One of the most significant elastomers with interesting strength, elasticity, durability, resilience, and abrasion resistance is Natural Rubber Latex (NRL). NRL refers to the white sap that comes from the tree of Hevea brasiliensis and has low intensity, softens in warm weather and brittle in cold weather and is almost limited in use in its original uncured form (Vandenplas and Raulf, 2017). NRL will

\footnotetext{
Department of Chemical Engineering,

College of Engineering, Universiti Malaysia Pahang,

Lebuhraya Tun Razak, 26300 Gambang,

Kuantan, Pahang, Malaysia.

2 Faculty of Chemical and Process Engineering Technology, College of Engineering Technology,

Universiti Malaysia Pahang, Lebuhraya Tun Razak, 26300 Gambang, Kuantan, Pahang, Malaysia.

* Corresponding author e-mail: knajwa@ump.edu.my
}

undergo vulcanisation, a chemical process where long chains of rubber molecules are cross-linked, transform the soft, weak plastic-like material into a strong elastic product with high and reversible deformability and good mechanical properties (Visakh et al., 2012). There are some latex products that have been carried into finished products by inadequate manufacturing processes that will result into pinholes or tear easily during the application of latex products in their field of work. The mechanical properties of NRL can be improved and tailored by crosslinking and addition of reinforcing fillers (Gopalan Nair and Dufresne, 2003).

It is proven that cellulose nanocrystal (CNC) have a distinct advantage for improving the mechanical properties of nanocomposites. Favier et al. (1995) first reported on the use of CNC as reinforcing agents in polymer composites which enhanced the mechanical properties of poly(styreneco-butyl acrylate) prepared via solvent casting processing of the corresponding latex. Their 
reinforcing effect, remarkable mechanical, chemical, and biocompatible properties as well as non-toxicity, biologically inertness, low density, biodegradability, surface functional groups, etc., could facilitate the application of CNC-filled nanocomposites as advanced materials. To enhance its mechanical properties, various polymer matrixes have been strengthened by CNC including NRL. CNC reinforced from various sources like wood (Mariano et al., 2016), cotton (Tian et al., 2017) and tunicate (Cao et al., 2018) were used to reinforce NRL.

Biomass such as empty fruit bunch (EFB) was also used a lot as a source to produce CNC (Gan et al., 2020; Shanmugarajah et al., 2015; Zulnazri et al., 2017). EFB is a good potential raw material for the $\mathrm{CNC}$ as the lignocellulosic constituents in EFB consist of high cellulose (24-65wt.\%) (Chang, 2014). In our previous work (Supian et al., 2020), EFB was used to produce cellulose nanofibre (CNF) and it has shown promising characteristics. It is likely that similar potential can be expected with $\mathrm{CNC}$ produced from EFB. Up to this date, there is no work yet that reported on CNC derived from EFB as reinforcing filler for NRL as well as investigation on the effect of curing temperature towards NRL nanocomposite.

In this work, $\mathrm{CNC}$ isolated using sulphuric acid hydrolysis from EFB was used as reinforcing filler. The CNC with volume fraction of 1,3 and $5 \mathrm{wt}$.\% were incorporated with NRL. The curing temperature effect at $70^{\circ} \mathrm{C}$ and $100^{\circ} \mathrm{C}$ were also investigated. The CNC size and dimension were measured and the performance of CNC/NRL nanocomposites was evaluated by the thermal, mechanical and swelling properties accordingly.

\section{MATERIALS AND METHODS}

\section{Materials}

High ammonia natural rubber was bought from Kinetic Chemicals (M) Sdn. Bhd., Malaysia while CNC were extracted from EFB's cellulose (Supian et al., 2020). Sulphuric acid $\left(\mathrm{H}_{2} \mathrm{SO}_{4}\right), 98 \%$ was purchased from Sigma Aldrich. The chemicals for rubber compounding which are zinc oxide $(\mathrm{ZnO})$, zinc dithiocaramate (ZDC), zinc mercapto benzothiazole (ZMBT), potassium hydroxide $(\mathrm{KOH})$ and sulphur were bought from Sigma Aldrich.

\section{Isolation of $\mathrm{CNC}$}

The isolation process using $\mathrm{H}_{2} \mathrm{SO}_{4}$ is adapted from Amin et al. (2017). Cellulose from EFB was stirred with deionised water. The solid to liquid ratio for this isolation process was 1:75. The $\mathrm{H}_{2} \mathrm{SO}_{4}$ was added slowly under vigorous mechanical stirring to cellulose until the final solution reached an acid concentration of $32 \%$. The ice bath was used to keep the temperature below $20^{\circ} \mathrm{C}$ while adding the acid. The mixture was heated for $3.5 \mathrm{hr}$ at $50^{\circ} \mathrm{C}$. The CNC suspension was cooled and centrifuged at $4750 \mathrm{rpm}$ four to five times until turbid. The suspension of $\mathrm{CNC}$ was dialysed against deionised water until the suspension reached the neutral state $(\mathrm{pH} 7)$. The $\mathrm{CNC}$ suspension was then subjected to ultrasonic using high intensity ultrasonic (QSonica ultrasonicator) for $30 \mathrm{~min}$ with an output of $500 \mathrm{~W}$, a frequency of $20 \mathrm{kHz}$ and amplitude of $20 \%$. Finally, the suspension of cellulose was lyophilised then dried using vacuum freeze dryer.

\section{Preparation of NRL Nanocomposites}

The NRL was stirred with other chemicals simultaneously as listed in Table 1 . Neat NRL (without $\mathrm{CNC}$ ) compounding was stirred within $30 \mathrm{~min}$ with speed of $35 \mathrm{rpm}$. NRL was poured into the beaker and stirred for $6 \mathrm{hr}$ at $12 \mathrm{rpm}$ until deaerated. Then, the steps were repeated for NRL nanocomposite by adding CNC with concentrations of 1,3 and $5 \mathrm{wt} . \%$ and was stirred for another 30 min.

CNC/NRL mixture was casted into flat glass mould and dried overnight at room temperature. Then, the dried film was dusted with calcium carbonate powder subsequently was leached for $10 \mathrm{~min}$ in distilled water, followed by being cured at two different temperatures, $70^{\circ} \mathrm{C}$ and $100^{\circ} \mathrm{C}$ in a convection oven under gentle purge of dry nitrogen for at least $4 \mathrm{hr}$. NRL films were rested at least $48 \mathrm{hr}$ at room temperature and $50 \%$ humidity before any further characterisation (Hosseinmardi et al., 2017). All the samples were labelled as CNC/NRL $X Y$ where $X$ was for curing temperature and $Y$ was for wt.\% of CNC.

\section{Characterisation}

Field emission scanning electron microscopy (FESEM) by JSM-7800F Schottky which operated up to $30 \mathrm{kV}$ and spot of $1.3 \mathrm{~nm}$ was employed to

TABLE 1. FORMULATION OF CNC/NRL NANOCOMPOSITE

\begin{tabular}{lcccc}
\hline Item & \multicolumn{4}{c}{ Weight $\%$ in nanocomposite } \\
\hline CNC weight (\%) & 0 & 1 & 3 & 5 \\
High ammonia NRL & 96.5 & 95.5 & 93.5 & 91.5 \\
Potassium hydroxide & 0.35 & 0.35 & 0.35 & 0.35 \\
solution & 1.5 & 1.5 & 1.5 & 1.5 \\
Sulphur & 0.75 & 0.75 & 0.75 & 0.75 \\
ZDC & 0.6 & 0.6 & 0.6 & 0.6 \\
ZMBT & 0.3 & 0.3 & 0.3 & 0.3 \\
ZnO & & & & \\
\hline
\end{tabular}


analyse morphology and dimension of CNC. The sample was prepared in powdery form and coated with platinum. The thermal stability of $\mathrm{CNC}$ was studied using a Mettler Toledo TGA/DSC1 using aluminium crucible standard $40 \mu \mathrm{L}$. A heating rate of $10^{\circ} \mathrm{C} \mathrm{min}^{-1}$ from $30^{\circ} \mathrm{C}$ to $700^{\circ} \mathrm{C}$ in air atmospheric condition was used. The $\mathrm{N}_{2}$ flow rate was 20 $\mathrm{mL} \mathrm{min}^{-1}$. Thermal degradation behaviour was then evaluated based on the weight loss against temperature. FT-IR was conducted on Spectrum 100 FT-IR to observe the changes in chemical bonding in NRL before and after the incorporation of CNC. The experiments were conducted with resolution being $4 \mathrm{~cm}^{-1}$ and the spectra was collected from 4000 to $500 \mathrm{~cm}^{-1}$.

The tensile testing of the composites was performed at room temperature using an Instron model 5543 universal testing equipped with $500 \mathrm{~N}$ load cell. The sample was cut into dumbbell shapes specimens according to ASTM D-412 (Varghese et al., 2004). The specimens of $40 \mathrm{~mm}$ length and $5 \mathrm{~mm}$ width were tested at a crosshead speed of $50 \mathrm{~mm} \mathrm{~min}^{-1}$, which corresponded to an initial strain rate of $10 \% \mathrm{~min}^{-1}$. A differential scanning calorimeter (DSC) Model Q1000 from TA Instruments was used to determine the thermal behaviour of $\mathrm{CNC} /$ NRL nanocomposite. All samples were analysed from $-80^{\circ} \mathrm{C}$ to $500^{\circ} \mathrm{C}$, at heating rate of $10^{\circ} \mathrm{C} \mathrm{min}^{-1}$ (Hajji et al., 1996). The toluene-swelling behaviour of the nanocomposites was conducted in toluene at ambient condition. The samples were weighed, immersed in toluene and removed every hour, gently blotted with paper towel, weighed, and immersed in toluene again immediately. Tolueneswelling behaviour was carried out for $8 \mathrm{hr}$ and was conducted in triplicate for each sample. The toluene uptake (SI) was determined from the Equation (1):

$$
\mathrm{SI}=\frac{W_{\mathrm{F}}-W_{0}}{W_{0}} \times 100 \%
$$

Where $W_{0}$ and $W_{F}$ are masses of the sample before immersion and immersed for a certain period $(\mathrm{t})$, respectively.

\section{RESULTS AND DISCUSSION}

\section{Morphology and Dimension of CNC}

Figure 1 shows a rod like shape of CNC was obtained via sulphuric acid hydrolysis. The size of $\mathrm{CNC}$ was calculated based on the average length and diameter of 100 random CNC particles using Image J software. Table 2 summarises the length, diameter, aspect ratio and the production yield of CNC based on the FESEM images. The value and shape obtained is in agreement with other CNC from different cellulose sources like corn husk (Kampeerapappun, 2015) and sugarcane bagasse (Kumar et al., 2014). However, CNC from EFB as reported by Gray et al. (2018) showed a slightly different result due to higher acid concentration $(62 \%)$ used in acid hydrolysis process.

\section{Thermal Stability of CNC}

Thermal degradation of cellulose materials or the reduction in mechanical properties at elevated temperatures is one of the major issues that limit their applications. The thermal stability of CNC

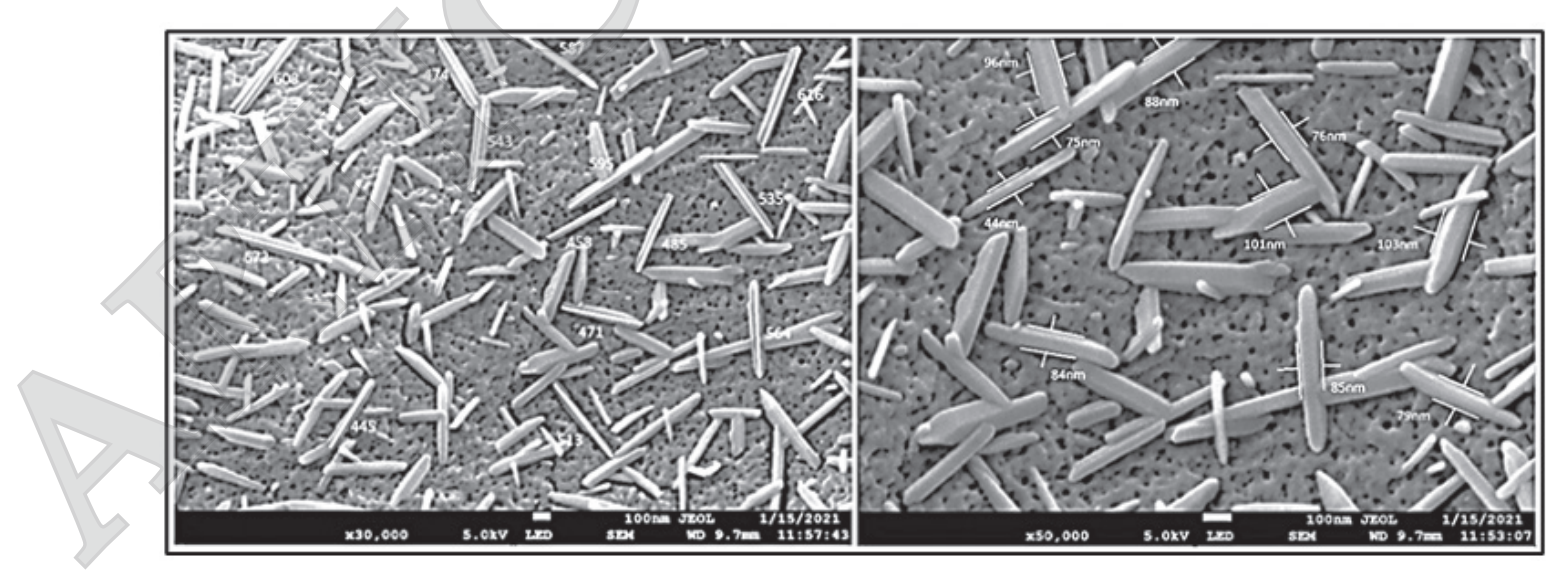

Figure 1. FESEM image of CNC from empty fruit bunch (EFB) via sulphuric acid hydrolysis at magnification of $15 \mathrm{kX}$ and $50 \mathrm{kX}$.

TABLE 2. DIMENSION AND PRODUCTION YIELD OF CNC ISOLATED FROM EFB

\begin{tabular}{lcccc}
\hline Sample & $\begin{array}{c}\text { Length } \\
(\mathbf{n m})\end{array}$ & $\begin{array}{c}\text { Diameter } \\
(\mathbf{n m})\end{array}$ & $\begin{array}{c}\text { Aspect ratio } \\
(\mathbf{L} / \mathbf{D})\end{array}$ & $\begin{array}{c}\text { Production yield } \\
(\%)\end{array}$ \\
\hline $\mathrm{CNC}$ & $672 \pm 445$ & $103 \pm 39$ & $11.4 \pm 6.5$ & 86 \\
\hline
\end{tabular}


was determined using TGA and the associated thermograms are shown in Figure 2. The CNC started to degrade at $180^{\circ} \mathrm{C}$ with maximum decomposition at around $300^{\circ} \mathrm{C}$. This degradation temperature was lower compared to the degradation temperature via phosphoric acid hydrolysis and mechanical method where recorded degradation temperatures were at $255^{\circ} \mathrm{C}$ and $258^{\circ} \mathrm{C}$, respectively (Amin et al., 2017). However, isolation of $\mathrm{CNC}$ by using sulphuric acid is well-known for giving advantages in terms of stable aqueous colloidal stability despite its poor thermal stability (Mao et al., 2017). In fact, in this work, the maximum processing temperature used was at $100^{\circ} \mathrm{C}$ (curing temperature), which was under degradation temperature of $\mathrm{CNC}$, thus, it would not disrupt the properties of $\mathrm{CNC}$.

CNC obtained from other various biomass resources were also found to have lower thermal stability than the CNC obtained from EFB. In studies conducted by Neto et al. (2013) and Song et al. (2019), CNC that was extracted from soy hulls and Calotropis procera (fruit) biomass recorded the degradation temperature of $160^{\circ} \mathrm{C}$ and $170^{\circ} \mathrm{C}$, respectively. Hence, the thermal stability of CNC from EFB in this work is verified to be much better than other nanocellulose from other biomass sources.

\section{Fourier-Transform Infrared Spectroscopy (FTIR) Analysis}

The FTIR spectra of NRL and CNC/NRL nanocomposites are shown in Figure 3 for both curing temperature of $70^{\circ} \mathrm{C}$ and $100^{\circ} \mathrm{C}$. The absorbance peaks recorded approximately between 3000 $\mathrm{cm}^{-1}$ and $3500 \mathrm{~cm}^{-1}$ are attributed to the stretching vibrations of $-\mathrm{OH}$ of $\mathrm{CNC}$. The adsorbed water

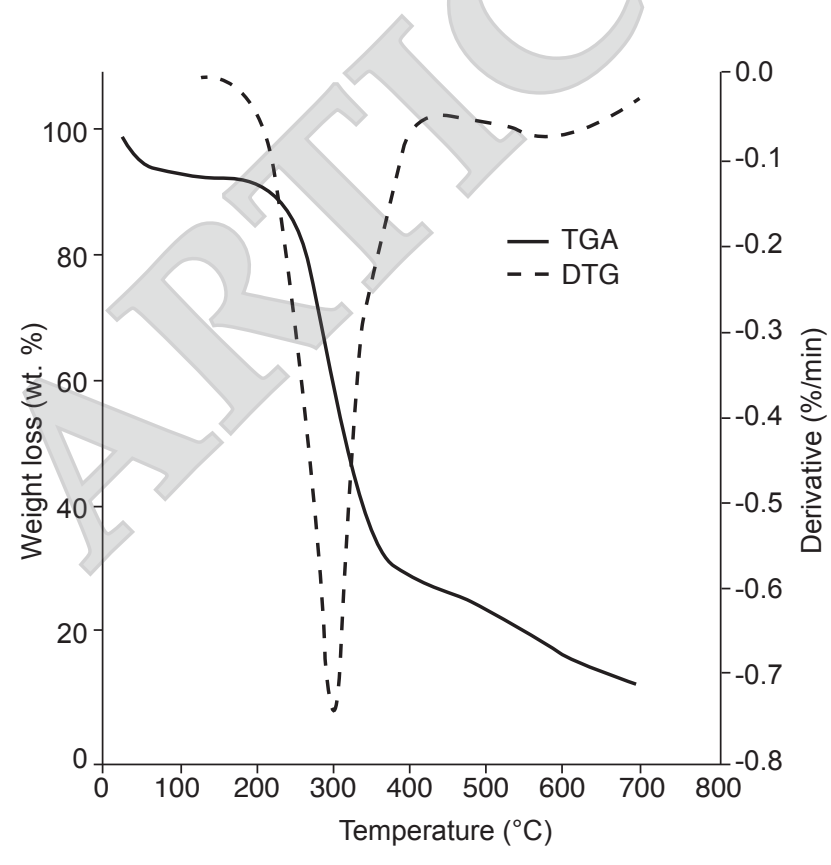

Figure 2. TGA and DTG curve of CNC. has also some contribution to the corresponding peak and its intensity is attributed to the hydroxyl group present in each cellulosic unit, similar result was shown by $\mathrm{Xu}$ et al. (2013). For both curing temperatures of nanocomposites, the peak intensity was increased with increasing $\mathrm{CNC}$ contents, indicating the incorporation of the CNC in NRL.

FTIR spectra of nanocomposites with $70^{\circ} \mathrm{C}$ and $100^{\circ} \mathrm{C}$ of curing temperature, the peaks are between 2850 to $2851 \mathrm{~cm}^{-1}, 1640$ to $1662 \mathrm{~cm}^{-1}$ and 2959 $\mathrm{cm}^{-1}$ which are assigned to $-\mathrm{CH} 3,-\mathrm{C}-\mathrm{H}$ and $=\mathrm{C}-\mathrm{H}$ stretching, respectively, and the peaks that show for -C-H bending is between 1425.96 to $1447.22 \mathrm{~cm}^{-1}$. There are peaks of -OH stretching between 3330.89 to $3394.64 \mathrm{~cm}^{-1}$ and C-O stretching between 1079.55 to $1084.49 \mathrm{~cm}^{-1}$.

These results of CNC/NRL nanocomposites show similar pattern as Abraham et al. (2013) and Jailudin and Amin (2020). In order for crosslinking of the rubber chains to occur, there has to be cleavage on some of the double bonds of the $=\mathrm{C}-\mathrm{H}$ groups and the appearance of -C-H groups must be observed (Blanchard et al., 2020) and these peak can be seen in Figure 3 (marked in red circle). A slight increase in the peak intensity of -C-H groups after the incorporation of $\mathrm{CNC}$ was also observed. In addition, the peak centered at $3380-3390 \mathrm{~cm}^{-1}$ and $1600-1500 \mathrm{~cm}^{-1}$ corresponding to the $-\mathrm{OH}$ stretching modes are much sharper and stronger, indicating higher densities of the hydroxyl groups on the surfaces of CNC (Agrebi et al., 2019). Other than that, there was no significant difference of peaks between the two curing temperatures at $70^{\circ} \mathrm{C}$ and $100^{\circ} \mathrm{C}$.

\section{Tensile Properties of CNC/NRL Nanocomposites}

The tensile properties of the CNC/NRL nanocomposites, as well as the pure NRL films, were characterised at room temperature. Tensile properties of CNC/NRL nanocomposites at two different curing temperatures are reported in Table 3. Figure 4 shows the stress vs. strain curves for these materials at $70^{\circ} \mathrm{C}$ and $100^{\circ} \mathrm{C}$.

At $70^{\circ} \mathrm{C}$ of curing temperature, the maximum tensile strength was achieved at $1 \mathrm{wt} . \%$ of $\mathrm{CNC}$ with $20 \%$ of improvement at 7.2 MPa. Meanwhile, the elongation at break and modulus recorded were $14 \%$ and $16 \%$ of improvement, respectively. Whereas for sample with $100^{\circ} \mathrm{C}$ of curing temperature, the maximum tensile strength, elongation at break and modulus were also achieved at $1 \mathrm{wt} . \%$ of $\mathrm{CNC}$ as well. Nevertheless, the value was slightly lower than curing temperature at $70^{\circ} \mathrm{C}$.

These significant improvements might be due to the reinforcing effect of $\mathrm{CNC}$ and its interaction with NRL on the molecular chain which became a good stress transfer agent that could provide higher strength (Blanchard et al., 2020). According to Thomas et al. (2015), CNC addition formed 
(a)
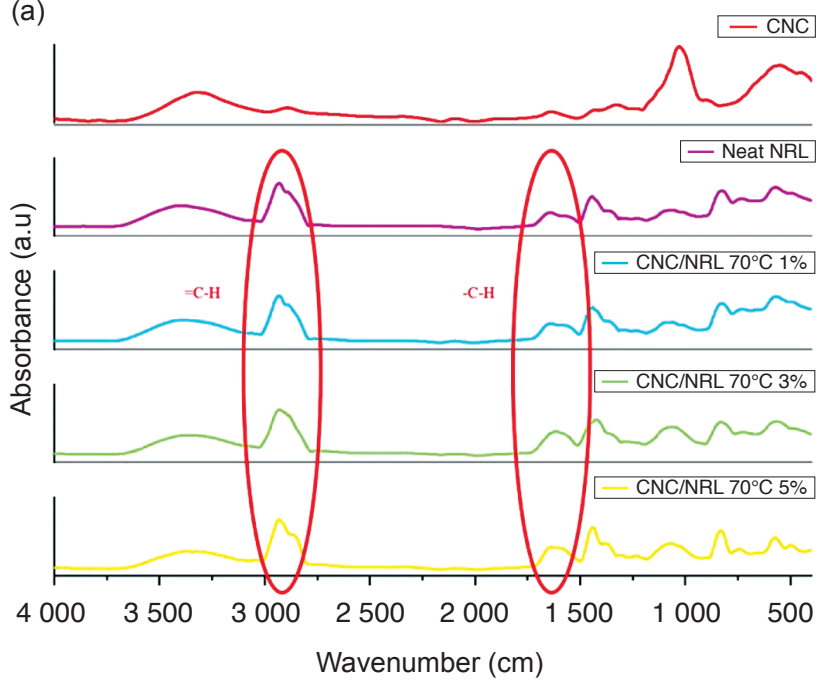

(b)



- Neat NRL

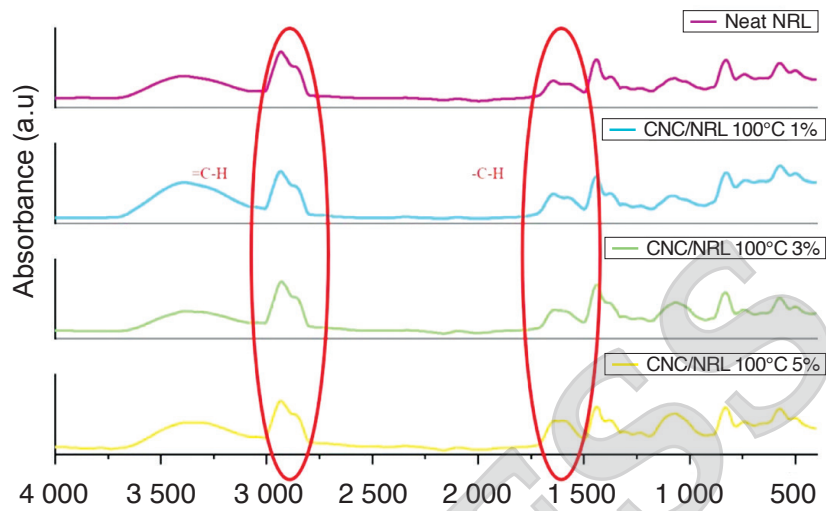

Wavenumber $(\mathrm{cm})$

Figure 3. FTIR spectra of CNC and CNC/NRL nanocomposites at curing temperature of (a) $70^{\circ} \mathrm{C}$, and (b) $100^{\circ} \mathrm{C}$.

TABLE 3. TENSILE PROPERTIES OF NEAT NRL AND CNC/NRL NANOCOMPOSITES

\begin{tabular}{lcccc}
\hline Curing temperature & $\begin{array}{c}\text { Sample } \\
(\boldsymbol{\%})\end{array}$ & $\begin{array}{c}\text { Tensile strength } \\
\mathbf{( M P a )}\end{array}$ & $\begin{array}{c}\text { Elongation } \\
\text { at break (\%) }\end{array}$ & $\begin{array}{c}\text { Young modulus, E } \\
\mathbf{( k P a )}\end{array}$ \\
\hline $70^{\circ} \mathrm{C}$ & Neat NRL & $6.0 \pm 0.2$ & $1225 \pm 29$ & 3.1 \\
& 1 & $7.2 \pm 0.2$ & $1398 \pm 50.4$ & 3.6 \\
& 3 & $2.4 \pm 0.4$ & $976 \pm 29$ & 3.4 \\
\hline $100^{\circ} \mathrm{C}$ & $1.8 \pm 0.3$ & $1025 \pm 66$ & 2.7 \\
\hline & Neat NRL & $4.9 \pm 0.3$ & $1206 \pm 76$ & 3.4 \\
& 1 & $6.9 \pm 1.4$ & $1247 \pm 77$ & 3.9 \\
& 3 & $3.6 \pm 0.5$ & $1059 \pm 47$ & 3.6 \\
\hline
\end{tabular}

(a)

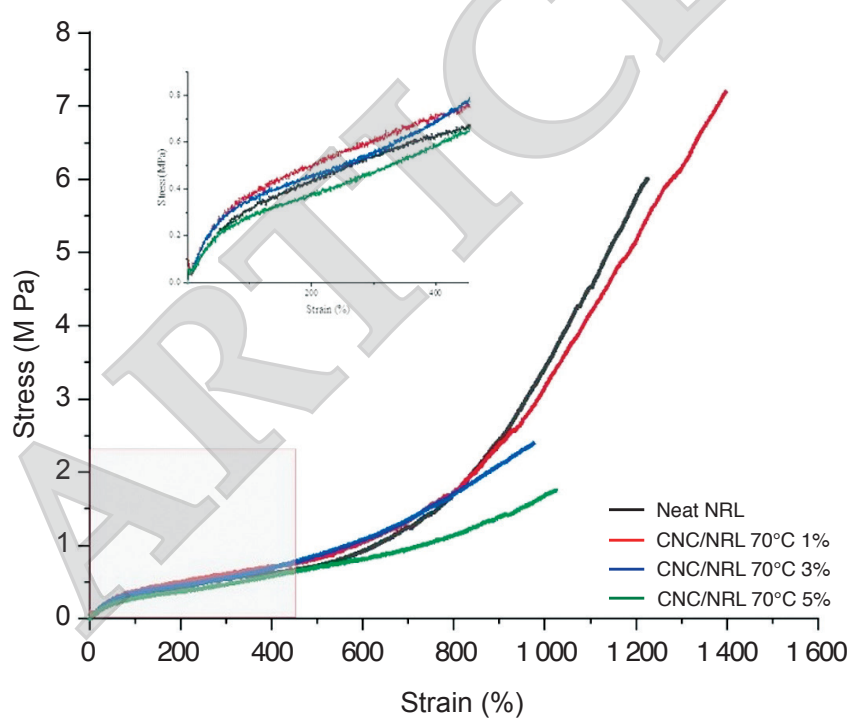

(b)

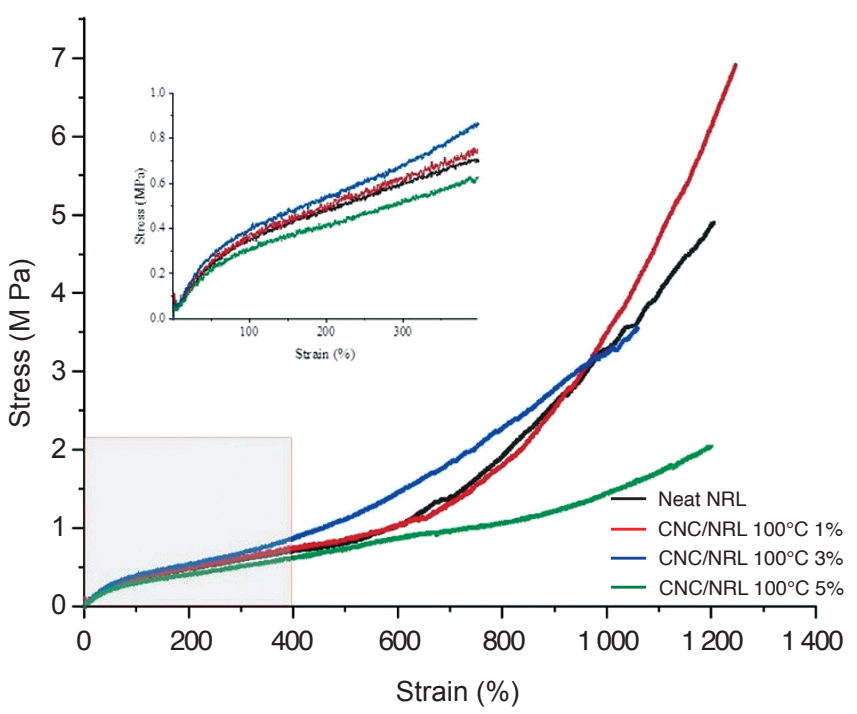

Figure 4. Stress-strain curve of CNC/NRL nanocomposites at curing temperature of (a) $70^{\circ} \mathrm{C}$, and (b) $100^{\circ} \mathrm{C}$.

percolation network within the polymer matrix and the interfacial interaction between matrix and CNC. Thus, the CNC-CNC and NRL-CNC reactions are both responsible to the mechanical enhancement of the resulting nanocomposites. Notably, for both curing temperatures, at 3\% and 
$5 \% \mathrm{CNC}$ addition decreased the tensile strength by more than $20 \%$. These results might be attributed by the possible restriction of polymer chain mobility in the vicinity of nanocrystal or due to agglomeration and its hydrophilicity characters (Zhang et al., 2014).

Table 4 shows the comparison of mechanical properties of $\mathrm{CNC} / \mathrm{NRL}$ nanocomposites from different types of cellulose sources. All nanocomposites show significant tensile strength improvement due to addition of additives or surface modification of CNC. However, the elongation at break results displayed significant reduction which sacrificed the ductility of NRL. This might be due to high loading of CNC in NRL matrix. Nonetheless, in this work, tensile strength was improved significantly as well as the elongation at break of the nanocomposite with only $1 \mathrm{wt} . \%$ of $\mathrm{CNC}$ loading and without any CNC modification or additives.

\section{Thermal Behaviour of CNC/NRL Nanocomposites}

The thermal behaviour of CNC/NRL nanocomposite was studied by DSC. Figure 5 displays the DSC curve for samples of NRL and $\mathrm{CNC} / \mathrm{NRL} 1 \mathrm{wt} . \%$ nanocomposites at $70^{\circ} \mathrm{C}$ and $100^{\circ} \mathrm{C}$ of curing temperatures.

Based on Figure 5, the glass transition temperature $\left(\mathrm{T}_{\mathrm{g}}\right)$ at $70^{\circ} \mathrm{C}$ of curing temperature recorded $-65.60^{\circ} \mathrm{C}$ and $-64.90^{\circ} \mathrm{C}$ for neat NRL and 1 wt. $\%$ CNC filled nanocomposite, respectively. Melting temperature $\left(\mathrm{T}_{\mathrm{m}}\right)$ for each film was around $-60^{\circ} \mathrm{C}$ whereas at $100^{\circ} \mathrm{C}$ curing temperature were at $-60.31^{\circ} \mathrm{C}$ and $-59.87^{\circ} \mathrm{C}$ for neat NRL and $1 \mathrm{wt} . \% \mathrm{CNC}$ filled NRL, respectively. Bendahou et al. (2010) reported that no significant variation of $\mathrm{T}_{\mathrm{g}}$ upon increasing content of CNC. In this study, similar results were also found for both curing temperatures of $70^{\circ} \mathrm{C}$ and $100^{\circ} \mathrm{C}$ displayed a $\mathrm{T}_{\mathrm{g}}$ around $-60^{\circ} \mathrm{C}$. Hence, the results are in agreement with previous observations on $\mathrm{CNC}$ filled nanocomposites where no modification on $\mathrm{T}_{\mathrm{g}}$ values was reported when increasing the $\mathrm{CNC}$ content regardless of the nature of the polymeric matric (Anglès and Dufresne, 2001). This also may indicate that CNC acted as reinforcing filler with only physical interaction/bonding with NRL and in agreement with the result from FTIR which also showed no change in terms of chemical bond after the addition of CNC in the NRL.

The value of $T_{g}$ will also affect the usage of the composite material, where polymers that have $T_{g}$ value below than $25^{\circ} \mathrm{C}$ will result in a soft, flexible polymer at ambient temperature. This statement is verified in this study where NRL and its nanocomposite recorded $\mathrm{T}_{\mathrm{g}}$ around $-60^{\circ} \mathrm{C}$ resulted in a rubbery-like texture which can be considered as soft and flexible polymer. Thus, in this study the $\mathrm{CNC}$ was not disrupting the molecular structure of the NRL and was able to retain the rubbery properties and improved the ductility of NRL.

\section{Swelling Behaviour of NRL Nanocomposites}

The toluene-swelling behaviour of neat NRL and CNC/NRL nanocomposite was also studied to observe the interaction of toluene with the rubber nanocomposite films, and the results are shown in Figure 6.

From the results, the toluene uptake at equilibrium state for both nanocomposites decreased gradually with increasing $\mathrm{CNC}$ content and this could be attributed by the higher interfacial interaction between CNC and NRL matrix (Colom et al., 2018) or possibility by the increase in crosslinking density (Blanchard et al., 2020) which can be seen in FTIR result. This is in agreement with the results that recorded the best tensile strength was at 1 wt. $\%$ of CNC. Meanwhile, CNC addition at 3 and $5 \mathrm{wt}$.\% reduced the swelling index and might be due to the increase of crosslink density of rubber which is not necessarily good. When heavily crosslinked, the rubber chain mobility becomes highly restricted and the chains are unable to dissipate heat generated by deformation through molecular motion, resulting in easy and brittle rapture at low elongation (Mok and Eng, 2018).

However, it cannot distinguish between the effect of chemical crosslinks or other factors such as entanglement as no significant changes can be seen from DSC result (Flink et al., 1988). It might also be that the swelling test affected by the area occupied by CNC molecules which is hydrophilic as well as strong matrix-filler interactions that can hinder

TABLE 4. MECHANICAL PROPERTIES OF CNC FROM DIFFERENT SOURCES

\begin{tabular}{|c|c|c|c|c|}
\hline \multirow{2}{*}{$\begin{array}{l}\text { Sources of } \\
\text { cellulose }\end{array}$} & \multirow{2}{*}{$\begin{array}{l}\text { Nanocellulose } \\
\text { loading }\end{array}$} & \multicolumn{2}{|c|}{ Mechanical properties of nanocomposites } & \multirow[t]{2}{*}{ Reference } \\
\hline & & $\begin{array}{l}\text { Improvement of } \\
\text { tensile strength } \\
\qquad(\%)\end{array}$ & $\begin{array}{c}\text { Reduction of } \\
\text { elongation at break } \\
(\%)\end{array}$ & \\
\hline Potato starch & 20 wt. $\%$ & 300 & 65 & Rajisha et al. (2014) \\
\hline Peanut shell & 3 wt. $\%$ & 30 & 14.3 & Chandra et al. (2020) \\
\hline Wood & $5 \mathrm{phr}$ & 200 & 33 & Blanchard et al. (2020) \\
\hline EFB & $1 \mathrm{wt} . \%$ & 20 & Improved $14 \%$ & This work \\
\hline
\end{tabular}


(a)

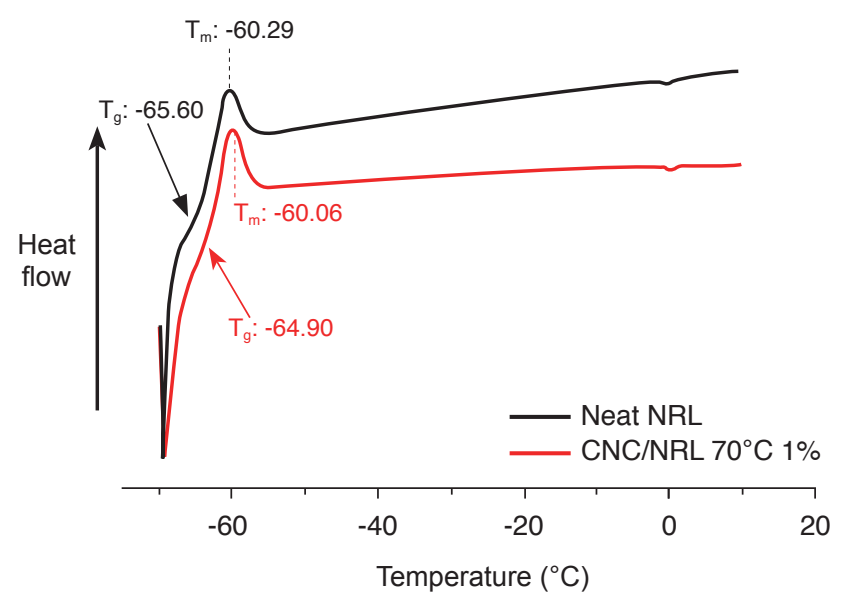

(b)

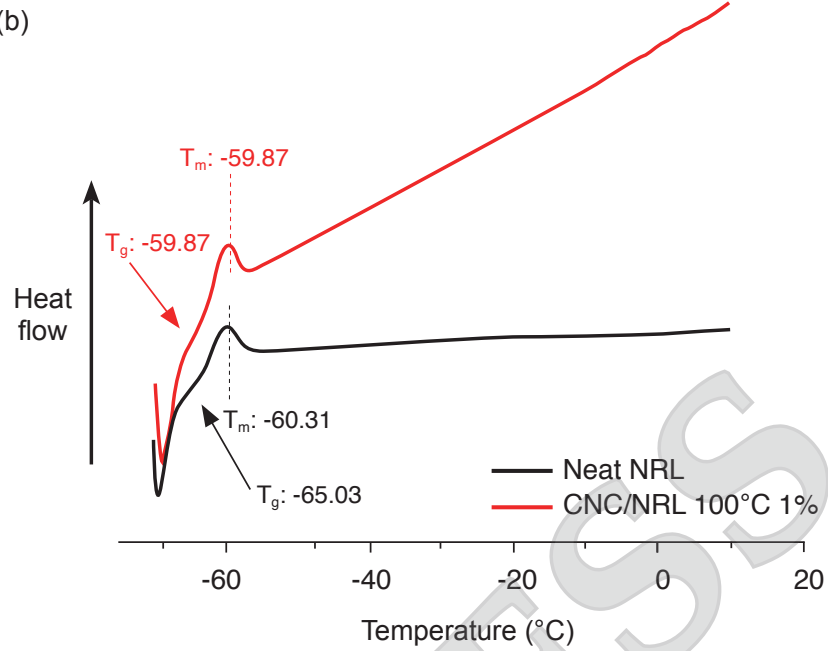

Figure 5. DSC curve of CNC/NRL nanocomposites at curing temperature of (a) $70^{\circ} \mathrm{C}$, and (b) $100^{\circ} \mathrm{C}$.

(a)

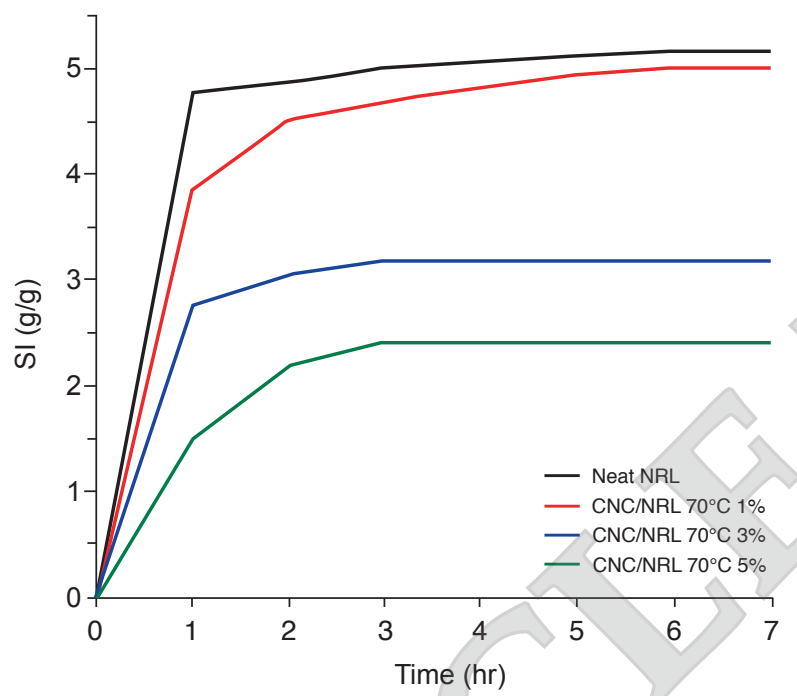

(b)

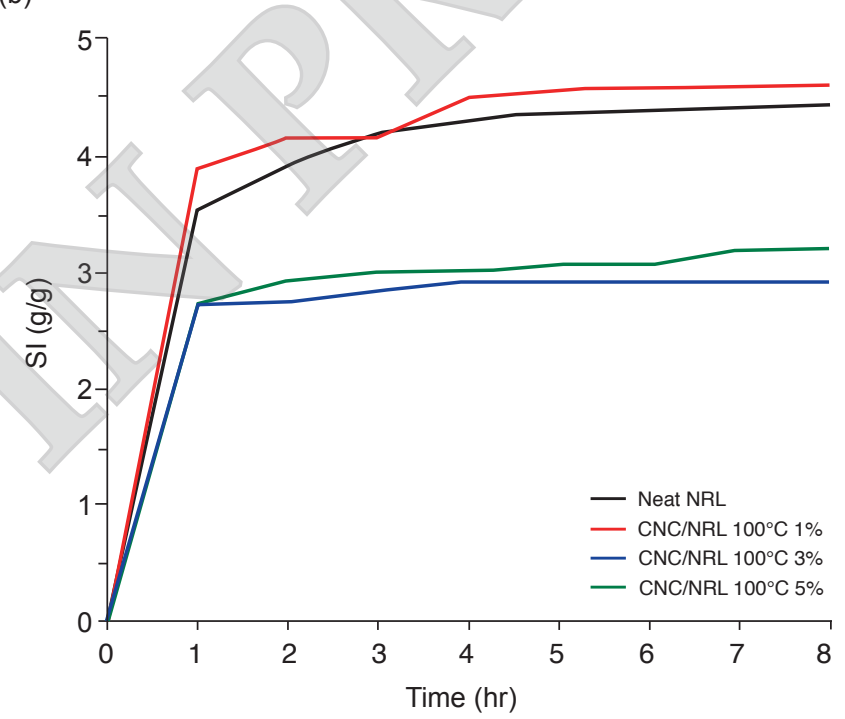

Figure 6. Swelling test OF CNC/NRL nanocomposites at curing temperature of (a) $70^{\circ} \mathrm{C}$, and (b) $100^{\circ} \mathrm{C}$.

solvent permeation in the rubber matrix, reducing the volume of the solvent absorbed (Cao et al., 2018).

Meanwhile, as comparison for both curing temperatures of $70^{\circ} \mathrm{C}$ and $100^{\circ} \mathrm{C}$, it showed similar swelling behaviour: toluene uptake increased in the first $4 \mathrm{hr}$ and then increased slowly until reaching the equilibrium state in day one and remained constant. However, for sample with $1 \mathrm{wt} . \%$ of CNC, it reached the equilibrium state after day 4 for both curing temperatures.

\section{CONCLUSION}

CNC in needle-like shape with an average length of $672 \pm 445 \mathrm{~nm}$ and diameter of $103 \pm 39 \mathrm{~nm}$ were successfully extracted from EFB cellulose via sulphuric acid hydrolysis. The best tensile strength was achieved at 1 wt.\% of CNC loading in NRL with $20 \%$ of improvement at $70^{\circ} \mathrm{C}$ of curing temperature. Thermal behaviour of CNC/NRL nanocomposites also did not show any significant changes indicating no chemical bonding can be identified. The toluene-swelling behaviour of neat NRL and CNC / NRL nanocomposites for both curing temperatures at $70^{\circ} \mathrm{C}$ and $100^{\circ} \mathrm{C}$ showed similar swelling behaviour: toluene uptake went up rapidly in the first $4 \mathrm{hr}$ and then increased slowly until reaching equilibrium state in one day. The swelling intake was reduced upon the CNC addition.

\section{ACKNOWLEDGEMENT}

The authors gratefully acknowledge the financial support by Ministry of Higher Education under Fundamental Research Grant Scheme (RDU1901120) / (FRGS/1/2019/TK05/UMP/02/3). 


\section{REFERENCES}

Abraham, E; Deepa, B; Pothan, L A; John, M; Narine, S S; Thomas, S and Anandjiwala, R (2013). Physicomechanical properties of nanocomposites based on cellulose nanofibre and natural rubber latex. Cellulose, 20(1): 417-427. DOI: $10.1007 /$ s10570012-9830-1.

Agrebi, F; Ghorbel, N; Bresson, S; Abbas, O and Kallel, A (2019). Study of nanocomposites based on cellulose nanoparticles and natural rubber latex by ATR/FTIR spectroscopy: The impact of reinforcement. Polym. Compos., 40(5): 2076-2087. DOI: 10.1002 / pc.24989.

Amin, K N M; Annamalai, P K and Martin, D (2017). Cellulose nanocrystals with enhanced thermal stability reinforced thermoplastic polyurethane. Malays. J. Anal. Sci., 21(3): 754-761.

Anglès, M N and Dufresne, A (2001). Plasticized starch/tunicin whiskers nanocomposite materials. 2. Mechanical behavior. Macromolecules, 34(9): 29212931. DOI: $10.1021 / \mathrm{ma} 001555 \mathrm{~h}$.

Bendahou, A; Kaddami, H and Dufresne, A (2010). Investigation on the effect of cellulosic nanoparticles' morphology on the properties of natural rubber based nanocomposites. Eur. Polym. J., 46(4): 609-620. DOI: 10.1016/j.eurpolymj.2009.12.025.

Blanchard, R; Ogunsona, E O; Hojabr, S; Berry, R and Mekonnen, T H (2020). Synergistic cross-linking and reinforcing enhancement of rubber latex with cellulose nanocrystals for glove applications. ACS Appl. Polym. Mater., 2(2): 887-898. DOI: 10.1021/ acsapm.9b01117.

Cao, L; Yuan, D; Fu, X and Chen, Y (2018). Green method to reinforce natural rubber with tunicate cellulose nanocrystals via one-pot reaction. Cellulose, 25(8): 4551-4563. DOI: 10.1007/s10570-018-1877-1.

Chandra, T; Harahap, H; Wangi, $\mathrm{Y}$ and Halimatuddahliana (2020). Physical and mechanical properties of natural rubber latex film (Rubber Dam) products with filler nanocrystal cellulose from peanut shell (Arachis hypogea L.) and synthetic dyes. IOP Conf. Ser.: Mater. Sci. Eng., 801(1): 012091.

Chang, S H (2014). An overview of empty fruit bunch from oil palm as feedstock for bio-oil production. Biomass Bioenergy, 62: 174-181. DOI: /10.1016/j. biombioe.2014.01.002.

Colom, X; Marín-Genescà, M; Mujal, R; Formela, $\mathrm{K}$ and Cañavate, J (2018). Structural and physicomechanical properties of natural rubber/GTR composites devulcanized by microwaves: Influence of GTR source and irradiation time. J. Compos. Mater., 52(22): 3099-3108. DOI: 10.1177/0021998318761554.

Favier, V; Canova, G R; Cavaillé, J Y; Chanzy, H; Dufresne, A and Gauthier, C (1995). Nanocomposite materials from latex and cellulose whiskers. Polym. Adv. Technol., 6(5): 351-355. DOI: 10.1002/ pat.1995.220060514.

Flink, P; Westerlind, B; Rigdahl, M and Stenberg, B (1988). Bonding of untreated cellulose fibers to natural rubber. J. Appl. Polym. Sci., 35(8): 2155-2164.

Gan, P G; Sam, S T; Abdullah, M F; Omar, M F and Tan, L S (2020). An alkaline deep eutectic solvent based on potassium carbonate and glycerol as pretreatment for the isolation of cellulose nanocrystals from empty fruit bunch. BioRes., 15(1): 1154-1170.

Gopalan Nair, K and Dufresne, A (2003). Crab shell chitin whisker reinforced natural rubber nanocomposites. 1. Processing and swelling behavior. Biomacromolecules, 4(3): 657-665. DOI: $10.1021 /$ bm020127b.

Gray, N; Hamzeh, Y; Kaboorani, A and Abdulkhani, A (2018). Influence of cellulose nanocrystal on strength and properties of low density polyethylene and thermoplastic starch composites. Ind. Crops Prod., 115: 298-305.

Hajji, P; Cavaillé, J Y; Favier, V; Gauthier, C and Vigier, G (1996). Tensile behavior of nanocomposites from latex and cellulose whiskers. Polym. Compos., 17(4): 612-619. DOI: 10.1002 / pc.10651.

Hosseinmardi, A; Annamalai, P K; Wang, L; Martin, $\mathrm{D}$ and Amiralian, N (2017). Reinforcement of natural rubber latex using lignocellulosic nanofibers isolated from spinifex grass. Nanoscale, 9(27): 9510-9519. DOI: 10.1039 / C7NR02632C.

Jailudin, N A H and Amin, K N M (2020). The effect of curing temperature on cellulose nanocrystal reinforced natural rubber latex. J. Chem. Eng. Ind. Biotechnol., 6(1): 20-25. DOI: 10.15282/jceib. v6i1.4875

Kampeerapappun, P (2015). Extraction and characterization of cellulose nanocrystals produced by acid hydrolysis from corn husk. J. Metals, Materials Minerals, 25(1): 19-26.

Kumar, A; Negi, Y S; Choudhary, V and Bhardwaj, N K (2014). Characterization of cellulose nanocrystals produced by acid-hydrolysis from sugarcane bagasse as agro-waste. J. Mater. Phys. Chem., 2(1): 1-8. 
Mao, H; Gong, Y; Liu, Y; Wang, S; Du, L and Wei, C (2017). Progress in nanocellulose preparation and application. Paper and Biomaterials, 2(4): 65-76.

Mariano, M; El Kissi, N and Dufresne, A (2016). Cellulose nanocrystal reinforced oxidized natural rubber nanocomposites. Carbohydr. Polym., 137: 174183.

Mok, K L and Eng, A H (2018). Characterisation of crosslinks in vulcanised rubbers: From simple to advanced techniques. Malays. J. Chem. (Mjchem), 20: 118-127.

Neto, W PF; Silvério, H A; Dantas, N O and Pasquini, D (2013). Extraction and characterization of cellulose nanocrystals from agro-industrial residue - Soy hulls. Ind. Crops Prod., 42: 480-488.

Rajisha, K R; Maria, H J; Pothan, L A; Ahmad, Z and Thomas, S (2014). Preparation and characterization of potato starch nanocrystal reinforced natural rubber nanocomposites. Int. J. Biol. Macromol., 67: 147-153. DOI: 10.1016/j.ijbiomac.2014.03.013.

Shanmugarajah, B; Kiew, P L; Chew, I M L; Choong, T S Y and Tan, K W (2015). Isolation of nanocrystalline cellulose (NCC) from palm oil empty fruit bunch (EFB): Preliminary result on FTIR and DLS analysis. Chem. Eng. Trans., 45: 1705-1710.

Song, K; Zhu, X; Zhu, W and Li, X (2019). Preparation and characterization of cellulose nanocrystal extracted from Calotropis procera biomass. Bioresour. Bioprocess., 6(1): 1-8.

Supian, M A F; Amin, K N M; Jamari, S S and Mohamad, S (2020). Production of cellulose nanofiber (CNF) from empty fruit bunch (EFB) via mechanical method. J. Environ. Chem. Eng., 8(1): 103024. DOI: $10.1016 / j . j e c e .2019 .103024$.

Thomas, MG; Abraham, E; Jyotishkumar, P; Maria, H J; Pothen, L A and Thomas, S (2015). Nanocelluloses from jute fibers and their nanocomposites with natural rubber: Preparation and characterization.
Int. J. Biol. Macromol., 81: 768-777. DOI: 10.1016/j. ijbiomac.2015.08.053.

Tian, M; Zhen, X; Wang, Z;Zou, H; Zhang, Land Ning, N (2017). Bioderived rubber-cellulose nanocrystal composites with tunable water-responsive adaptive mechanical behavior. ACS Appl. Mater. Interfaces, 9(7): 6482-6487.

Vandenplas, O and Raulf, M (2017). Occupational latex allergy: The current state of affairs. Curr. Allergy Asthma Rep., 17(3): 14. DOI: 10.1007/s11882017-0682-5.

Varghese, S; Gatos, K G; Apostolov, A A and KargerKocsis, J (2004). Morphology and mechanical properties of layered silicate reinforced natural and polyurethane rubber blends produced by latex compounding. J. Appl. Polym. Sci., 92(1): 543-551. DOI: 10.1002 / app.20036.

Visakh, P M; Thomas, S; Oksman, K and Mathew, AP (2012). Crosslinked natural rubber nanocomposites reinforced with cellulose whiskers isolated from bamboo waste: Processing and mechanical / thermal properties. Compos. Part A: Appl. Sci. Manuf., 43(4): 735-741. DOI: 10.1016/j.compositesa.2011.12.015.

Xu, X; Liu, F; Jiang, L; Zhu, J Y; Haagenson, D and Wiesenborn, D P (2013). Cellulose nanocrystals vs. cellulose nanofibrils: A comparative study on their microstructures and effects as polymer reinforcing agents. ACS Appl. Mater. Interfaces, 5(8): 2999-3009. DOI: 10.1021 / am302624t.

Zhang, C; Dan, Y; Peng, J; Turng, L-S; Sabo, R and Clemons, C (2014). Thermal and mechanical properties of natural rubber composites reinforced with cellulose nanocrystals from Southern Pine. Adv. Polym. Technol., 33(S1). DOI: 10.1002/adv.21448.

Zulnazri, Z; Anjana, F and Roesyadi, A (2017). Temperature effect of crystalinity in cellulose nanocrystal from oil palm empty fruit bunch (OPEFB) using sonication-hydrothermal methods. J. Pure Appl. Chem. Res., 6(1): 14-21. 